\title{
Band gap, energy storage density, dielectric and ferroelectric properties study of nano and micro-scale Lanthanum doped PZT
}

\author{
Shibnath Samanta*, V. Sankaranarayanan and K. Sethupathi
}

Low Temperature Physics Laboratory, Department of Physics, Indian Institute of Technology Madras, Chennai-36

*Email: shibnath@physics.iitm.ac.in,shibnaths2@gmail.com

Lanthanum doped lead zirconium titanate is studied extensively for its wide variety of application in DRAM, FRAM, IR sensor, electro-optic devices, energy harvesting and thermo-electric device applications [1,2]. Doping $8 \%$ of Lanthanum in lead zirconium titanate $\left(\mathrm{PbZr}_{0.65} \mathrm{Ti}_{0.35}\right)$ exhibits unique optical properties with respect to other pure or doped PZTs. The $\quad 8 \%$ Lanthanum-doped $\left(\mathrm{PbZr}_{0.65} \mathrm{Ti}_{0.35}\right)$ nano particles were prepared by sol-gel synthesis using alkoxide precursors. Pure phase formation start at $600{ }^{\circ} \mathrm{C}$. In order to see importance of particle size the samples were prepared at different temperatures from $600{ }^{\circ} \mathrm{C}$ to $900{ }^{\circ} \mathrm{C}$. Figure 1 shows pure phase or nano PLZT at $700{ }^{\circ} \mathrm{C}$ and $800{ }^{\circ} \mathrm{C}$.

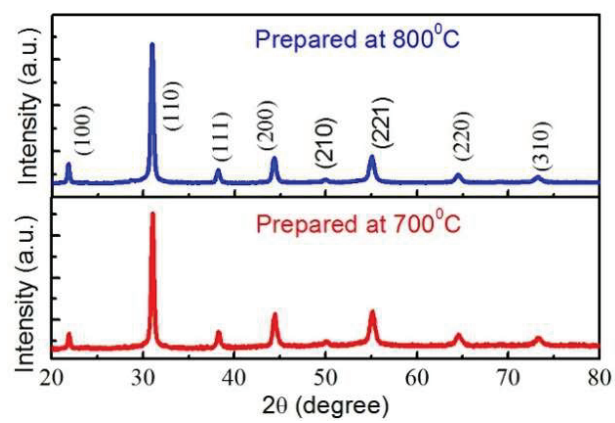

Figure 1: XRD pattern of PLZT nanoparticles prepared at $700{ }^{\circ} \mathrm{C}$ and $800{ }^{\circ} \mathrm{C}$

The nano powder was pressed and sintered at $1200{ }^{\circ} \mathrm{C}$ to get micro particles. The sintering was done using lead atmosphere to prevent lead loss during high temperature treatment. Morphology of both nano particles and bulk was examined by scanning electron microscopy. Temperature variation of dielectric measurement was carried out in the range from $30{ }^{\circ} \mathrm{C}$ to $300{ }^{\circ} \mathrm{C}$ in the frequency range $100 \mathrm{~Hz}$ to $10 \mathrm{MHz}$. The Curie temperature (Tc) was found to be $\sim 120{ }^{\circ} \mathrm{C}$. At room temperature, the polarization vs. electric field study was carried out. From dielectric study the Tc was found to change with frequency and polarization study shows slim tilted P-E loop, which confirms the relaxor nature of La-doped lead zirconium titanate [3].

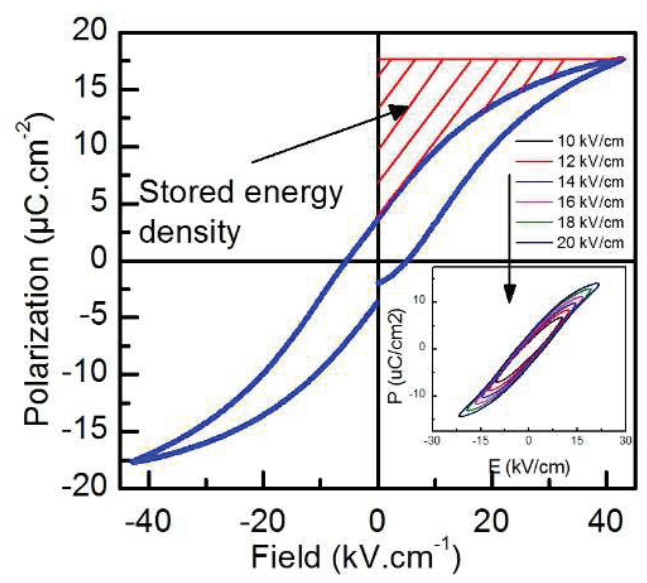

Figure 2: P-E loop and stored energy of PLZT micro particles sintered at $1150{ }^{\circ} \mathrm{C}$

Energy storage density calculation was carried out from the P-E loops (Figure 2). Band gap of nanoparticles as well as micro-particles was determined by diffuse reflectance spectroscopy.

\section{References}

1. R. Thomas, S. Mochizuki, T. Mihara, and T. Ishida, Thin Solid Films 443, 14 (2003).

2. W.-D. Yang, Ceram. Int. 27, 373 (2001).

3. S. Kamba, V. Bovtun, J. Petzelt, I. Rychetsky, R. Mizaras, A. Brilingas, J. Banys, J. Grigas, and M.

Kosec, J. Phys.: Condens. Matter 12, 497 (2000). 